\title{
OR 2020 - Die schweizerische Schuldrechtsreform aus vergleichender Sicht
}

\author{
Hrsg. v. Jan Dirk Harke u. Karl Riesenhuber
}

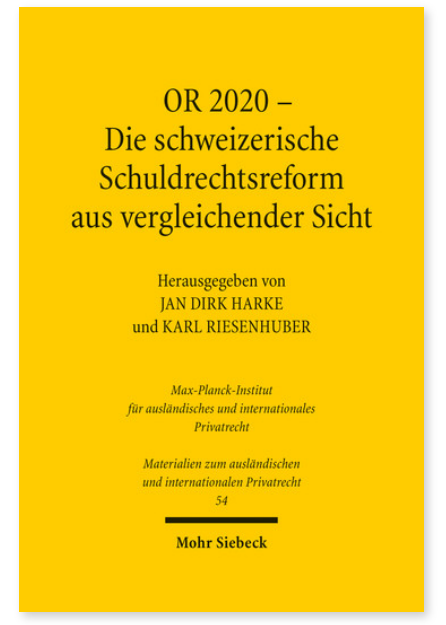

2016. IX, 317 Seiten. MatIPR 54

ISBN 978-3-16-154213-8

DOI 10.1628/978-3-16-154213-8

eBook PDF 94,00€

ISBN 978-3-16-154212-1

Leinen $94,00 €$
Rechtswissenschaftler aller Schweizer Fakultäten haben 2013 einen Entwurf für ein reformiertes Obligationenrecht (Allgemeiner Teil) vorgelegt. Der Entwurf verdient die Würdigung auch aus dem Ausland. Er enthält darüber hinaus aber auch eine Fülle von Anregungen für die Zivilrechtsordnungen anderer Länder sowie die Entwicklung eines Europäischen Schuldrechts. (Die mehrsprachige Version des Entwurfs ist unter www.or2020.ch einsehbar). Neben einer Einführung aus schweizerischer Sicht enthält der Band die Beiträge deutscher Rechtswissenschaftler, in denen ausgewählte Fragen aus allen zentralen Regelungsgebieten erörtert werden.

Inhaltsübersicht

Claire Huguenin: Einführung: OR 2020 - Thomas Pfeiffer: Bürger, Verbraucher, Europa - Karl Riesenhuber: Vertragsschluss (Antragsprinzip, Form und vorformulierte Klauseln) - Jan Dirk Harke: Willensmängel und Geschäftsgrundlage - Andreas Piekenbrock: Verjährung und Verwirkung - Florian Faust: Leistungsstörungen - Martin Schwab: Liquidation und Bereicherungsrecht - Karl-Nikolaus Peifer: Das Deliktsrecht als Gegenstand des Allgemeinen Teils

Jan Dirk Harke ist Inhaber des Lehrstuhls für Bürgerliches Recht, Römisches Recht und Historische Rechtsvergleichung an der Universität Würzburg.

Karl Riesenhuber ist Inhaber des Lehrstuhls für Bürgerliches Recht, Deutsches und Europäisches Handels- und Wirtschaftsrecht an der Ruhr-Universität Bochum.

Jetzt bestellen:

https://mohrsiebeck.com/buch/or-2020-die-schweizerische-schuldrechtsreform-aus-vergleichender-sicht-9783161542138? no_cache=1

order@mohrsiebeck.com

Telefon: +49 (0)7071-923-17

Telefax: $+49(0) 7071-51104$ 